\author{
Classification \\ Physics Abstracts \\ $68.48-81.20 \mathrm{~L}-61.16 \mathrm{D}$
}

\title{
HRTEM studies on oxide ceramics
}

\author{
Daniel Michel, Léo Mazerolles and Richard Portier \\ CNRS - CECM, 15 rue Georges Urbain, 94407 Vitry, France
}

(Received October 01, 1990; accepted January 25, 1991)

\begin{abstract}
Résumé. - La microscopie électronique en transmission à haute résolution a été utilisée pour l'étude de la structure locale dans des céramiques oxydes. Des renseignements à l'échelle du nanomètre sont obtenus à partir des images et de leur interprétation après simulation du contraste. Ces travaux concernent, d'une part la structure d'interfaces alumine-zircone et mullite-verre, d'autre part la mise en évidence de domaines d'ordre dans des phases de type mullite.
\end{abstract}

\begin{abstract}
HRTEM techniques have been applied to investigate the local structure in some oxide ceramics. Information at a nanometric scale is drawn from high resolution images and their interpretation after contrast simulation. Some of these studies concern the atomic structure of interfaces between zirconia and alumina and between mullite crystals and a silica-rich glass. Other results are related to local order in mullite phases.
\end{abstract}

\section{Introduction.}

Ceramics containing alumina, zirconia, mullite are interesting materials for thermomechanical applications due to high melting point an high strength. Contrary to nitrides or carbides they can withstand oxidizing atmospheres without a significant decrease of their mechanical properties. High resolution transmission electron microscopy (HRTEM) allows to study these materials at a nanometer scale and to reveal fine details on their microstructure and their local atomic structure. In this paper, we report results on the interfaces between alumina and zirconia and between mullite and glass. Other results concern the order phenomena observed in mullites. The structure of mullite contains oxygen vacancies which are more or less ordered. Long and short range order arrangements are observed by analysis of diffuse scattering and HRTEM images.

\section{Experimental.}

The samples for observations of interfaces are prepared by directional solidification from the melt. The oxides are melt using either direct induction at high frequency or arc imaging. Experimental details on these techniques are reported previously [1]. Specimens are prepared by mechanical polishing of oriented platelets followed by argon ion milling. 
HRTEM observations are carried out on a JEOL 200CX microscope provided with a high resolution pole piece. The spherical aberration coefficient $C_{\mathrm{s}}$ is $1 \mathrm{~mm}$. Image simulation is performed using a program based on a Bloch wave formalism [2]. The beam divergence and the chromatic defocus are estimated to be respectively $1 \mathrm{mrad}$ and $7.5 \mathrm{~nm}$.

Digital images can be directly recorded from the microscope with a LHESA camera and a CRYSTAL frame store. An optical pick-up system also allows to digitize images from zones selected on negative films. Images are processed with a SEMPER program. Filtering can be used in order to reduce noise or extract specific features from the images. In particular, areas of interest can be selected in reciprocal space for image reconstruction by inverse Fourier transform. This technique has been applied in particular to reveal ordered domains in mullite phases.

\section{Results and discussion.}

3.1 INTERFACES ALUMINA-ZIRCONIA. - The dispersion of zirconia particles in alumina leads to materials with enhanced strength and toughness. In order to obtain structure images of one phase, it is necessary that the specimen be oriented with dense atomic rows parallel to the electron beam and that the spacing between these rows is higher than the microscope resolution. Moreover, these conditions have to be satisfied for both phases when heterophase interfaces are studied. Unidirectional solidification generally induces oriented microstructures and low energy interfaces which can be directly observed by HRTEM on transverse sections. In particular, very regular microstructures are obtained at eutectic compositions. In most cases, defined orientation relations between the constituent phases are found. They generally correspond to a perfect alignment of crystallographic axes with low Miller indices. These relations are reviewed in a recent paper on oxide-eutectics [1].

Figure 1 shows the microstructure of an aligned eutectic consisting of an alumina matrix and particles of cubic zirconia stabilised by yttria. The volume fraction of the zirconia particles is about 0.65 . The alumina matrix as well as the zirconia particles are perfectly aligned along the crystallographic axes [0110] $\mathrm{Al}_{2} \mathrm{O}_{3} / /$ [001] $\mathrm{ZrO}_{2}$ which are parallel to the freezing direction. Electron diffraction indicates that the relative orientation of the two phases is (2i10) $\mathrm{Al}_{2} \mathrm{O}_{3} / /$ (100) $\mathrm{ZrO}_{2}$ and [0001] $\mathrm{Al}_{2} \mathrm{O}_{3} / /$ [010] $\mathrm{ZrO}_{2}$ (3). In figure 1, vertical interfaces between zirconia and alumina are large faces corresponding to (2110) $\mathrm{Al}_{2} \mathrm{O}_{3} / /(100) \mathrm{ZrO}_{2}$ planes. The interface deviates from this perfect orientation in the rounded parts of the zirconia particles. TEM studies reveal that facets and steps are formed in those regions, as shown in figure 2 at the transition between a planar low-energy interface and an inclined part of the interface.

A bidimensional coincidence lattice for the interface is drawn from electron diffraction and HRTEM images. The corresponding rectangular supercell is represented in figure 3 . The lattice mismatch is maximal along the [0001] $\mathrm{Al}_{2} \mathrm{O}_{3} / /[010] \mathrm{ZrO}_{2}$ direction, but it only amounts to $1 \%$.

The structure on both sides of a planar alumina-zirconia interface seen on edge appears on the high resolution TEM image of figure 4. The calculated diffraction of the corresponding digitized image (Fig. 4b), which is just the superimposition of the contribution of each crystal, shows the coincidence between lattice planes perpendicular to the interface in both structures. This coincidence is also clearly exhibited in figure $4 \mathrm{c}$ obtained by reconstruction from the Fourier transform of figure $4 \mathrm{a}$ after selecting only the spots \pm 0003 and \pm 0006 of alumina and \pm 020 of zirconia. In projection along the [0110] $\mathrm{Al}_{2} \mathrm{O}_{3} / /[001] \mathrm{ZrO}_{2}$ direction, cubic zirconia has a square lattice with spacing $0.257 \mathrm{~nm}$ (half the unit-cell parameter) and alumina has a rectangular lattice with spacings of $0.433 \mathrm{~nm}$ (one third of the $c$ unit-cell parameter) along the interface and $0.238 \mathrm{~nm}$ (half the $a$ unit-cell parameter) perpendicular to the interface. Simulation of contrast allows to assign the bright dots on the images to the projection of oxygen atom rows. From this results, an 


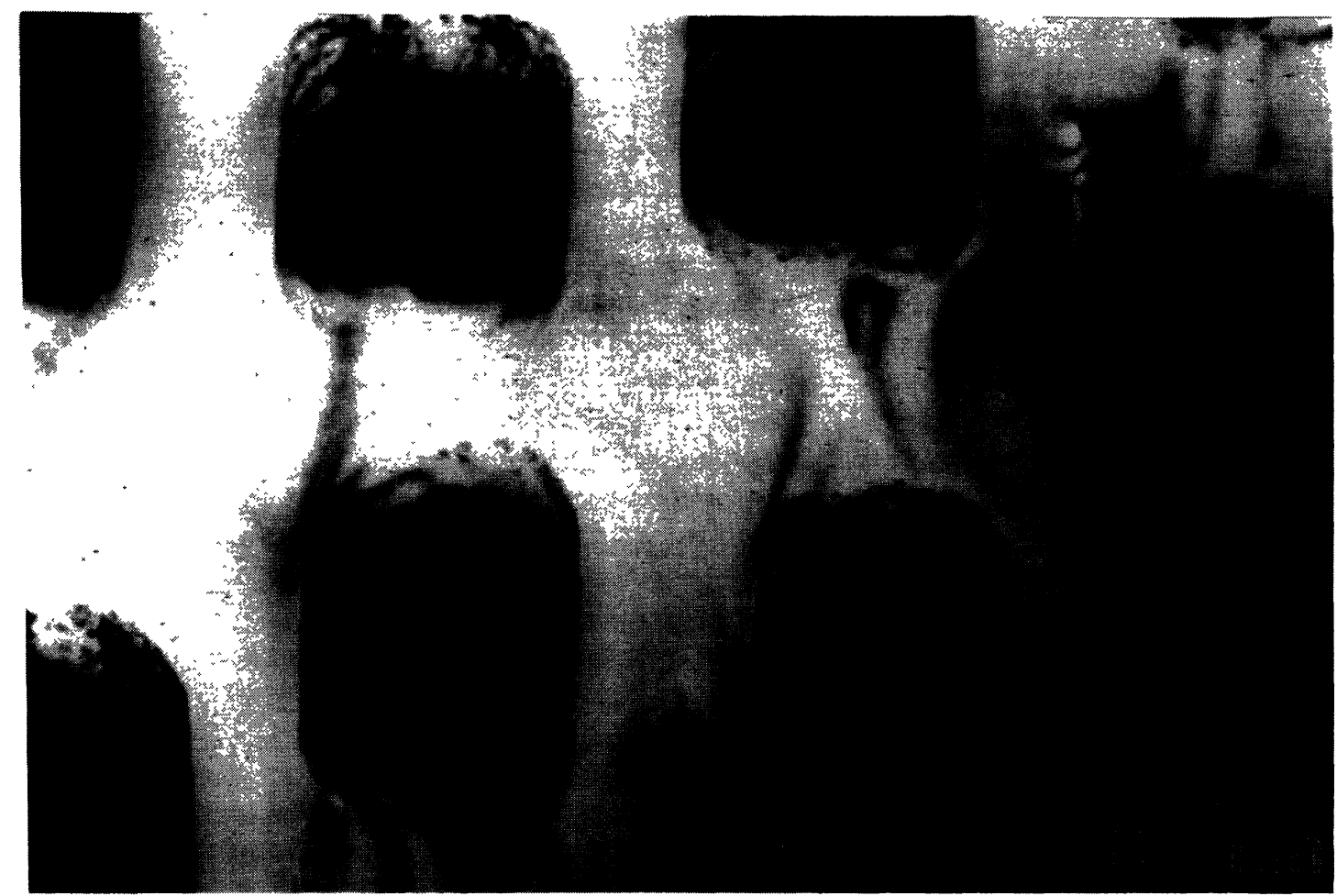

Fig. 1. - Microstructure of an aligned eutectic with composition $62 \mathrm{~mol} \% \mathrm{Al}_{2} \mathrm{O}_{3}, 34.5 \mathrm{~mol} \% \mathrm{ZrO}_{2}$, $3.5 \mathrm{~mol} \% \mathrm{Y}_{2} \mathrm{O}_{3}$ consisting of cubic zirconia particles dispersed in an alumina matrix. TEM images of a section perpendicular to the growth direction $[01 \overline{1} 0] \mathrm{Al}_{2} \mathrm{O}_{3} / /[001] \mathrm{ZrO}_{2}$.

atomic model leading to satisfactory interatomic distances can be proposed for a planar perfect interface [4].

As previously shown in figure 2, inclined interfaces are observed in other regions of the composite. An example is given by the HRTEM image of figure 5a. On the diffraction corresponding to the 2-D image (Fig. 5b), a slight misorientation (about $2^{\circ}$ ) is observed between the two lattices.

This misalignment is visible in figure $5 \mathrm{c}$ which is reconstructed from the Fourier transform using the same spots as in figure 4c. In addition to the diffraction spots of alumina and zirconia, extra spots indicated by arrows in figure $5 \mathrm{~b}$ are observed at one third and two thirds of the $\pm 0006 \mathrm{Al}_{2} \mathrm{O}_{3}$ reflections. They result from multiple dynamical diffraction of both crystals in the overlapping region and are associated to the moire-like contrast observed in the experimental image. This is confirmed by the Fourier inversion performed with these spots in addition with those used for figure 5c. In this case, an additional periodic contrast is found at the level of the overlapping region (Fig. 5d) with the coincidence periodicity of $1.3 \mathrm{~nm}$ previously mentioned.

3.2 GLASS-MULLITE INTERFACES. - Directional solidification in the alumina-silica system leads to samples consisting of a silica-rich glass and mullite crystals. The proportion and the size of crystals depend on the chemical composition and experimental conditions. Details on the microsctructures obtained are given elsewhere $[5,6]$. Mullite crystals have a typical needle-like morphology with the elongation direction along the $c$ axis of the orthorhombic structure. This direction is 


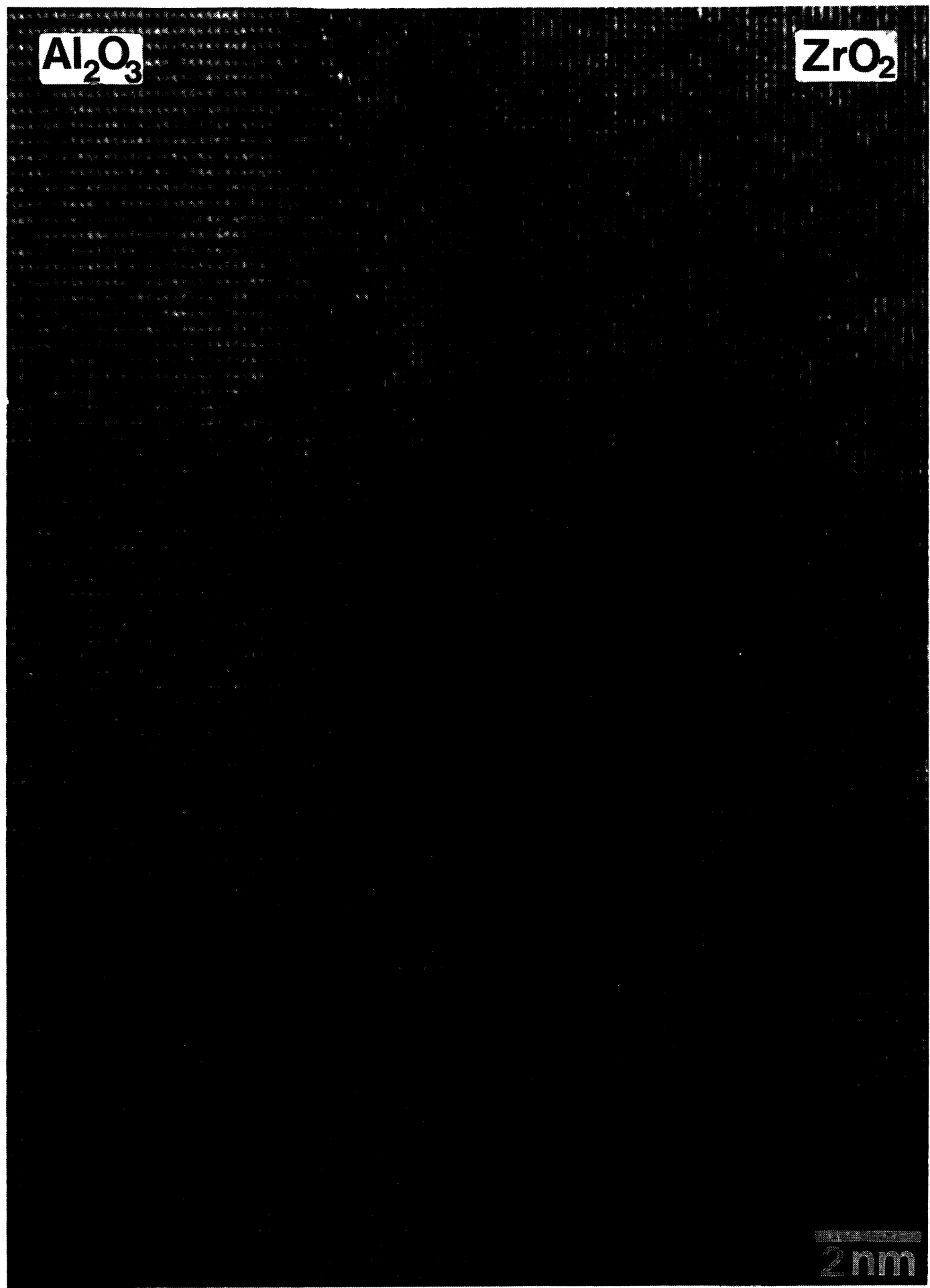

Fig. 2. - HRTEM image of the transition from a planar boundary to a faceted and stepped interface in zirconia-alumina. Section perpendicular to the growth direction [0110] $\mathrm{Al}_{2} \mathrm{O}_{3} / /[001] \mathrm{ZrO}_{2}$. 


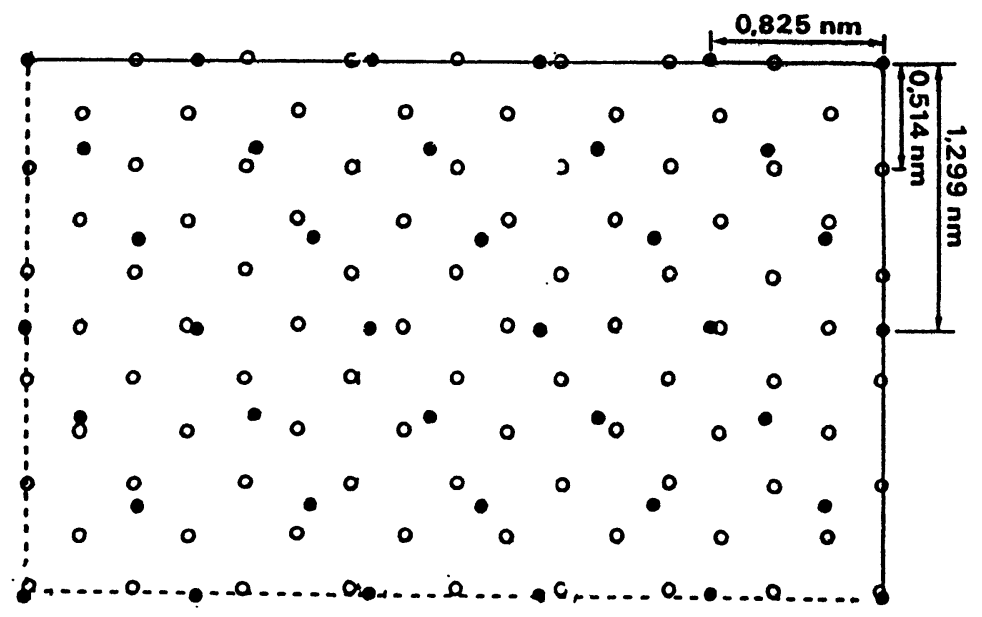

Fig. 3. - Projection of zirconia and alumina lattice nodes on the (2īio) $\mathrm{Al}_{2} \mathrm{O}_{3} / /(100) \mathrm{ZrO}_{2}$. interface plane $\left(\mathrm{Al}_{2} \mathrm{O}_{3}: \bullet, \mathrm{ZrO}_{2}: \circ\right)$. The coincidence supercell for lattice fit within $1 \%$ is indicated.
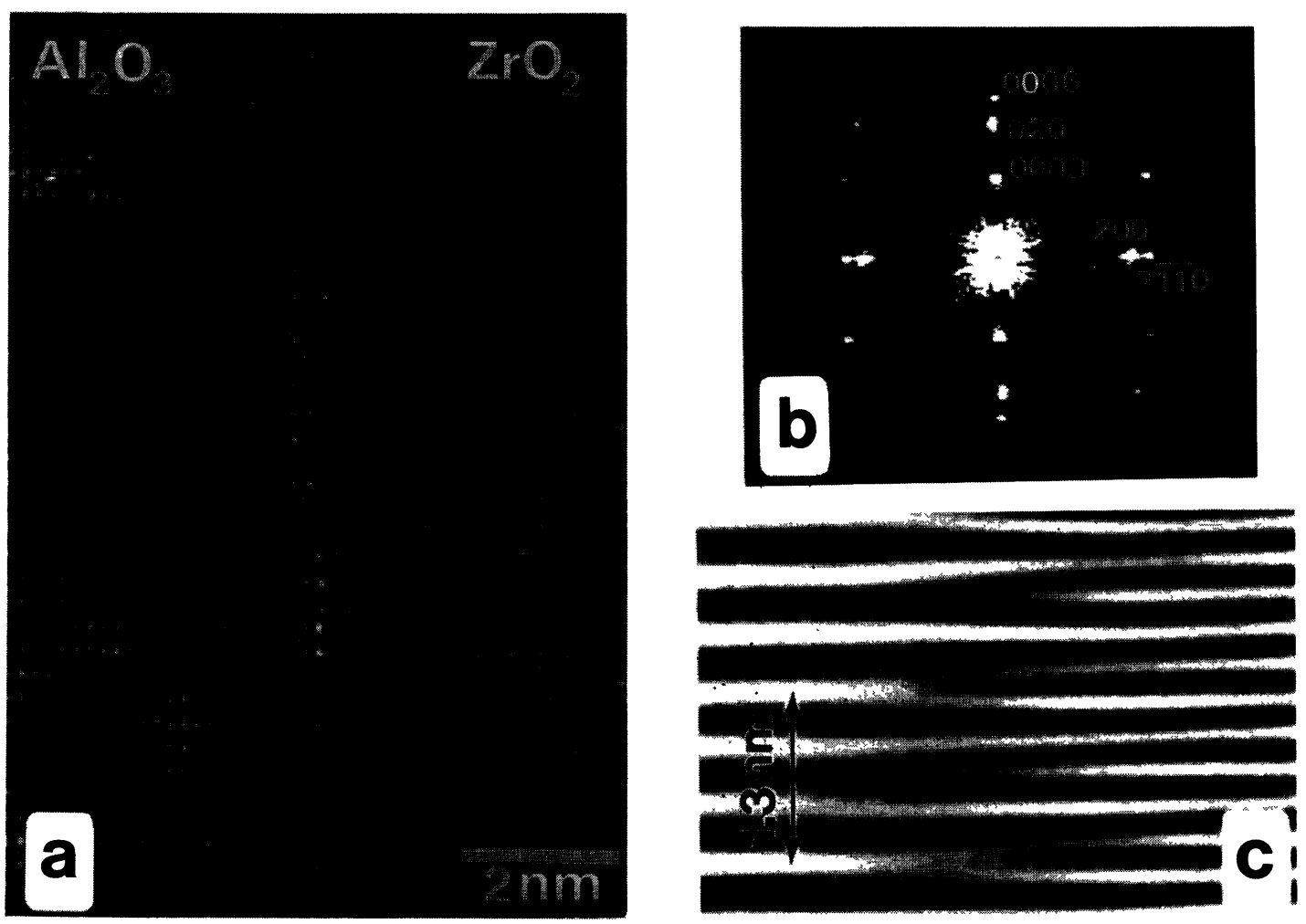

Fig. 4. - HRTEM image of a planar zirconia-alumina interface: a) original image, b) diffraction of the 2$D$ digitized image $c$ ) image reconstructed by Fourier inversion in selecting the spots \pm 0003 and \pm 0006 of alumina and \pm 020 of zirconia in reciprocal space. 

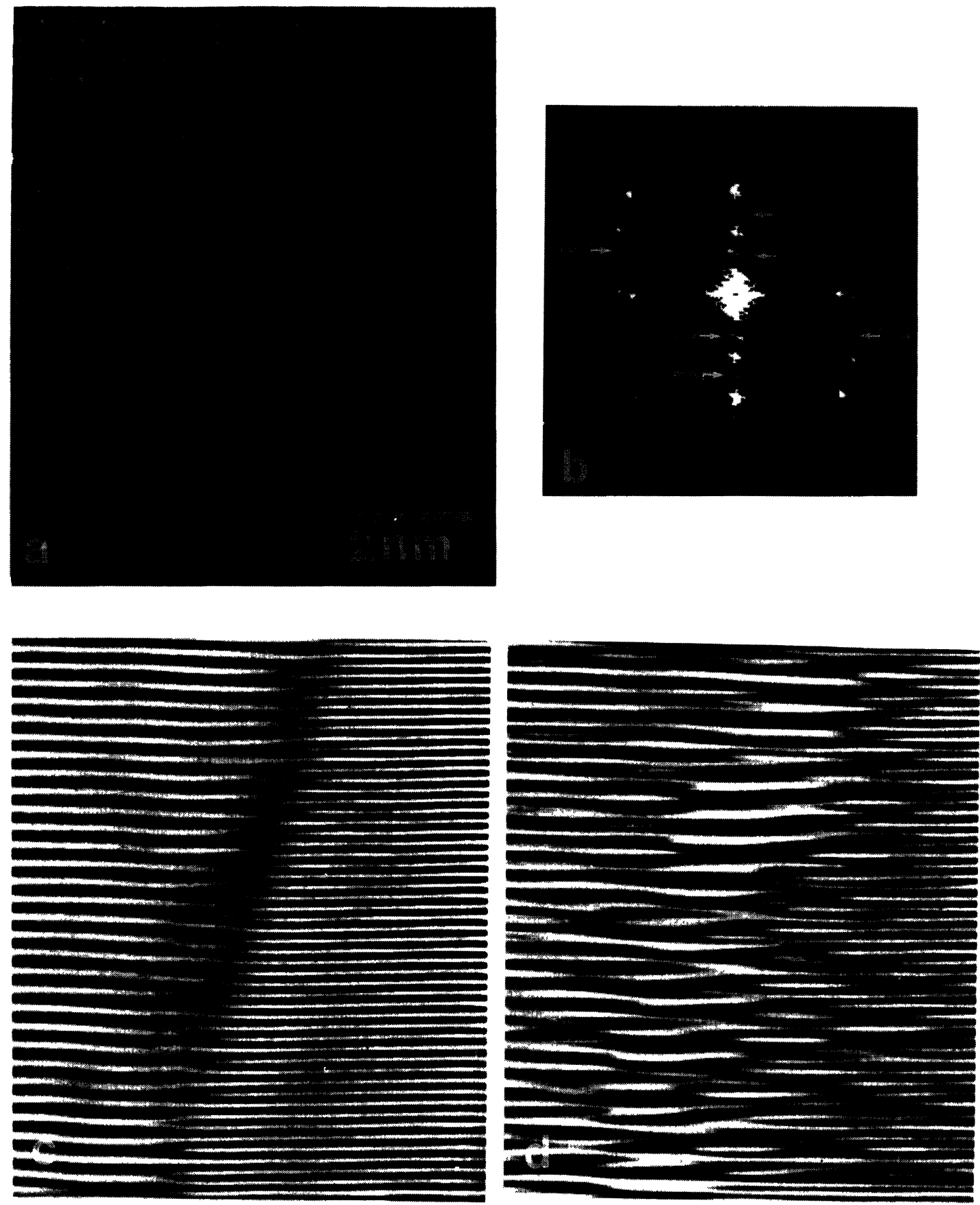

Fig. 5. - HRTEM image of a non-planar interface (same orientation as Fig. 4) a) original image, b) diffraction of the 2-D digitized image, c) image reconstructed by Fourier inversion in selecting the spots \pm 0003 and \pm 0006 of alumina and \pm 020 of zirconia, d) image reconstructed with the previous spots and the extra spots indicated by arrows which arise from the interfacial superstructure. 
parallel to the chains of edge-sharing octahedra and corner-sharing tetrahedra forming the structure. Interfaces between glass and mullite are observed on (001) transverse sections of oriented samples. The lateral faces of parallelepipedic crystals or dendrites are $\{110\}$ planes (Fig. 6a at low magnification and $6 \mathrm{~b}$ at high resolution).

HRTEM observations and image simulations of mullite on the (001) plane are reported by several authors $[4,7-10]$. In the thinner zones of the specimen, details of contrast agree with the through focus-thickness simulation reported in reference [4]. However, in the vicinity of the glassmullite interface, a larger thickness and some beam tilt due to charge problems reduce the contrast to an array of bright dots with the lattice periodicity. The position of these spots corresponds on the image to the projection of octahedral chains. This allows to propose the atomic model given in inset in figure 7.

3.3 LOCAL ORDER IN MULLITE. - Mullite is not a compound with a defined composition. Its is an oxygen-deficient phase $\mathrm{Al}_{4+2 x} \mathrm{Si}_{2-2 x} \mathrm{O}_{10-x}$ which can be prepared with compositions between $3 \mathrm{Al}_{2} \mathrm{O}_{3}-2 \mathrm{SiO}_{2}(x=0.25)$ and $5 \mathrm{Al}_{2} \mathrm{O}_{3}-2 \mathrm{SiO}_{2}(x=0.5)$. Its structure is related to that of sillimanite $\mathrm{Al}_{2} \mathrm{SiO}_{5}$, with oxygen vacancies on particular oxygen sites and variable aluminium/silicon ratio.

The X-ray or electron diffraction patterns of mullite contain fundamental spots characteristic of the average structure and additional diffuse scattering. The average structure of mullite is well established from refinement using the intensity of fundamental spots [11]. However, the local arrangements of oxygen vacancies is not still completely known. As the scattering features are more or less intense and diffuse depending on the composition and thermal history of the sample, various degrees of order are present in mullites. In particular, Ylä-Jääski and Nissen have observed mullite superstructures in oxygen vacancy-rich mullites by HRTEM [12]. They have interpreted the images by contrast simulation and proposed models for vacancy ordering. Similar results have been recently obtained on germanium mullites [13]. Figure 8a shows an ordered zone corresponding to a superstructure with ideal composition $\mathrm{Al}_{10} \mathrm{Ge}_{2} \mathrm{O}_{19}$. The lattice constants of the supercell are $4 a_{\text {mullite }}, b_{\text {mullite }}$ and $2 c_{\text {mullite }}$. Image simulation (Fig. $8 \mathrm{~b}$ ) confirms an atomic model similar to that previously described for silicon mullite [12] assuming vacancy ordering in rows parallel to the [010] direction [13].

For composition with lower vacancy rates, such ordered arrangements are no longer observed and the periodicity of dots on HRTEM images is that of the projection of the average mullite structure. For the (010) plane, the spacings are $c_{\text {mullite }}=0.29 \mathrm{~nm}$ along [001] and $a_{\text {mullite }} / 2=$ $0.38 \mathrm{~nm}$ along [100]. However, with particular defocus conditions, some dots present an enhanced intensity. This phenomenon has been related to the diffuse scattering visible on diffraction pattern (Fig. 9a) using digital processing of images. Figure 10a shows a digital HRTEM image where the intensity of white dots is not constant. An image is reconstructed by Fourier inversion in selecting only regions of reciprocal space with diffuse scattering by circular masks with appropriate size (Fig. 9b). This process allows to extract the information relative to the fluctuations of dot intensity. Figure 10b shows that this treatment reveals ordered domains with a size of a few nanometers. The contrast inside these domains is similar to that previously observed in long range ordered mullites. If these domains contain a higher concentration of oxygen vacancies, this would indicate that most mullites are not chemically homogeneous at the nanometer scale and that the observed structure could result from a tendency to a phase separation which does not develop at long range for kinetic reasons. 

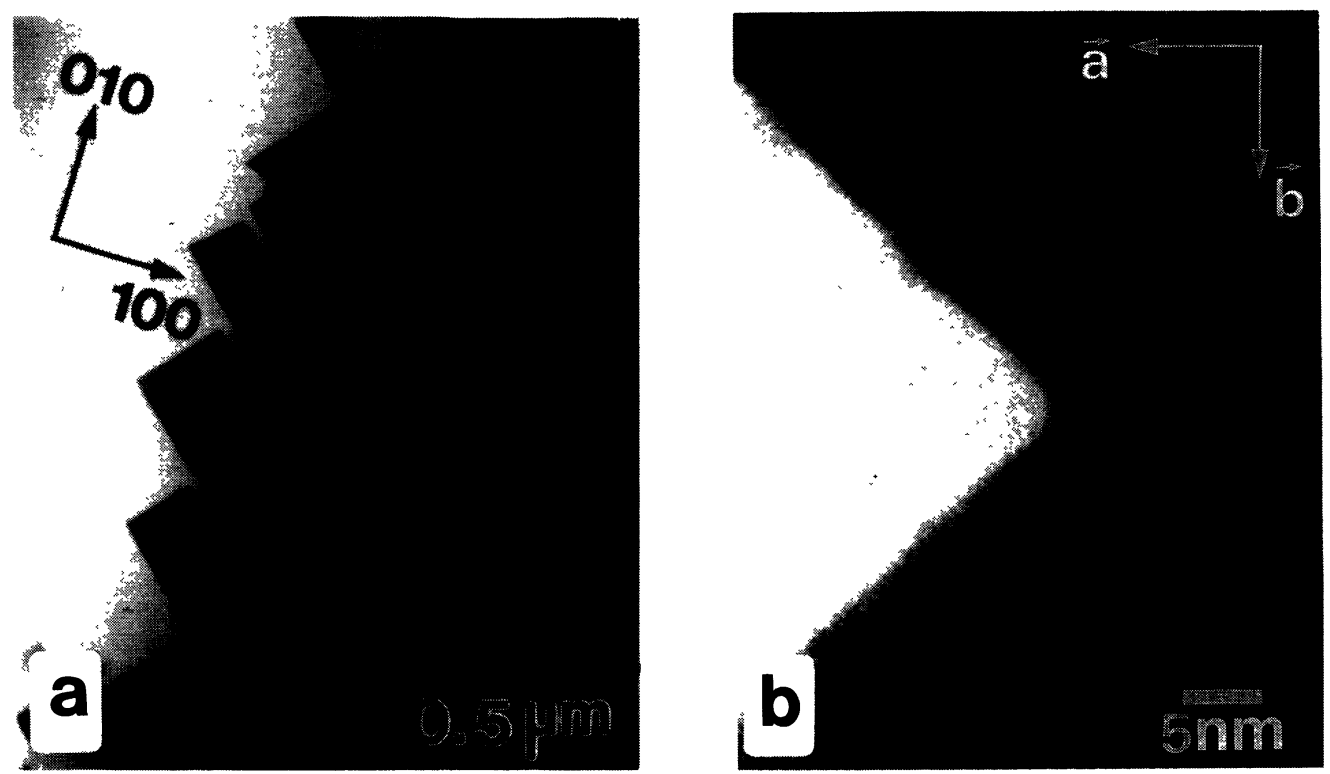

Fig. 6. - Transverse section of a sample obtained by directional solidification at the composition $72 \mathrm{~mol} \%$ $\mathrm{SiO}_{2}-28 \% \mathrm{~mol} \% \mathrm{Al}_{2} \mathrm{O}_{3}$ : a) mullite dendrite in a glassy matrix b) HRTEM image of the interface.

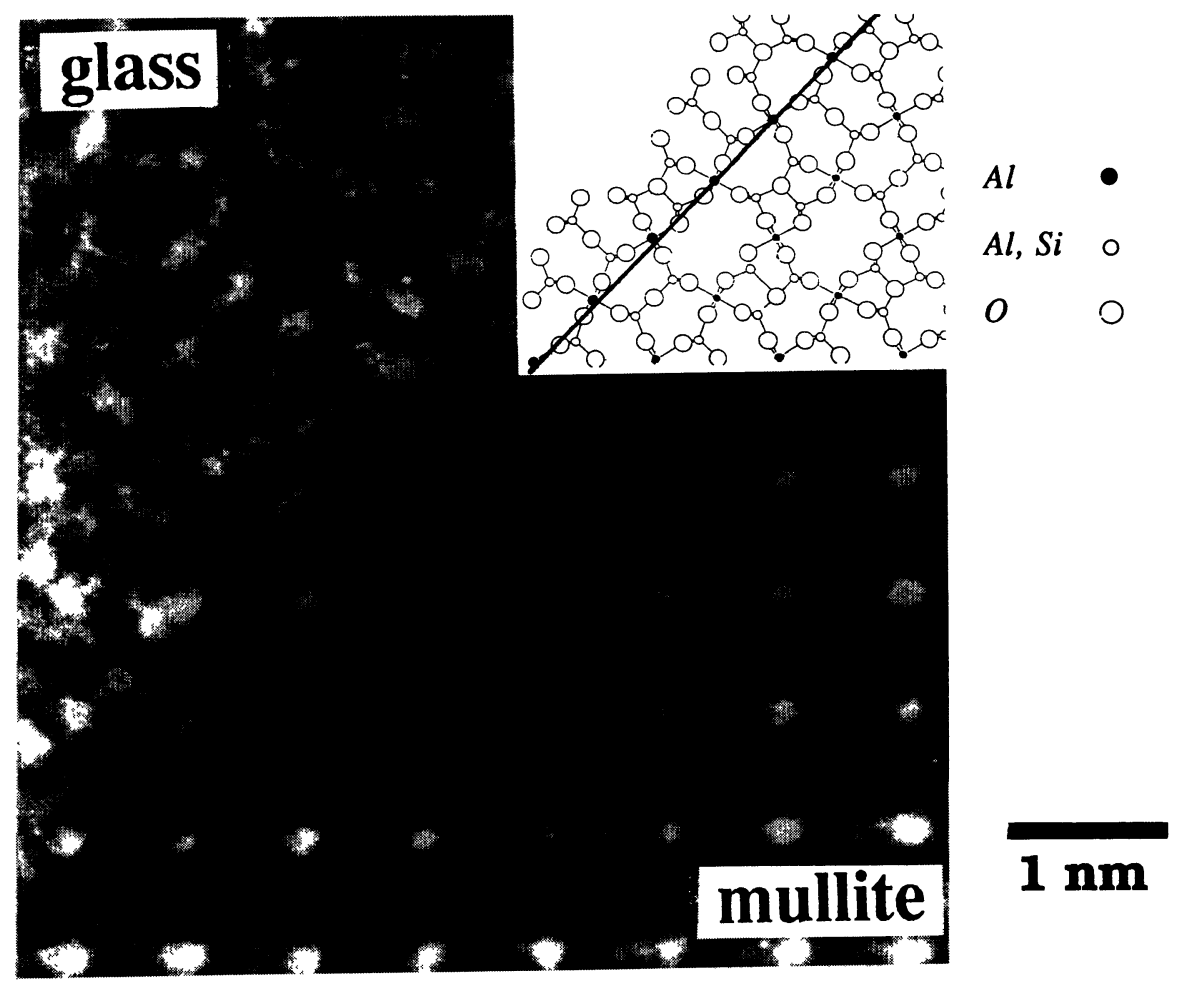

Fig. 7. - High resolution image of a glass-mullite interface with the atomic model in inset. 

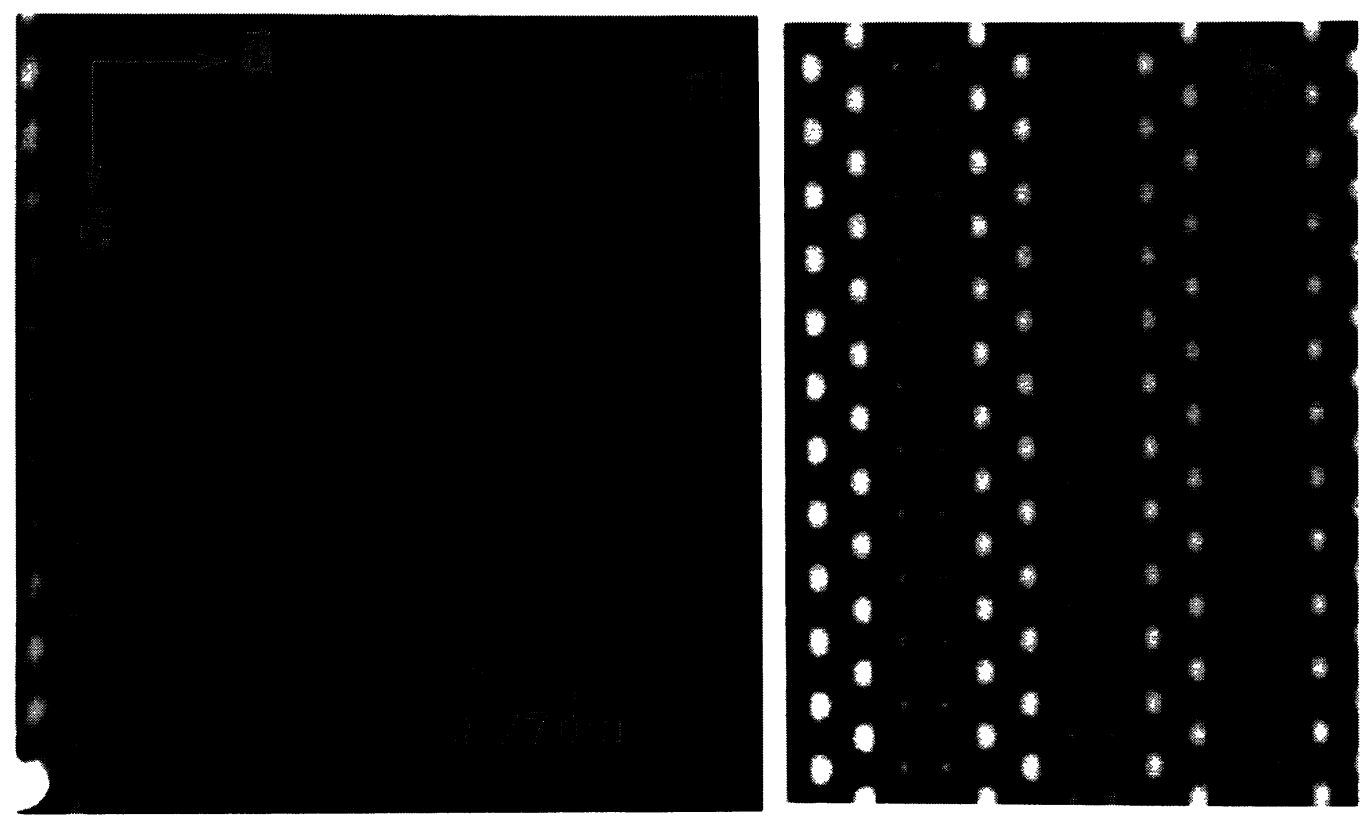

Fig. 8. - Ordered germanium mullite: a) HRTEM image of the (010) plane, b) image of the superstructure simulated for a thickness of $15 \mathrm{~nm}$ and an underfocus of $30 \mathrm{~nm}$. The brighter spots correspond to zigzag rows of oxygen vacancies.
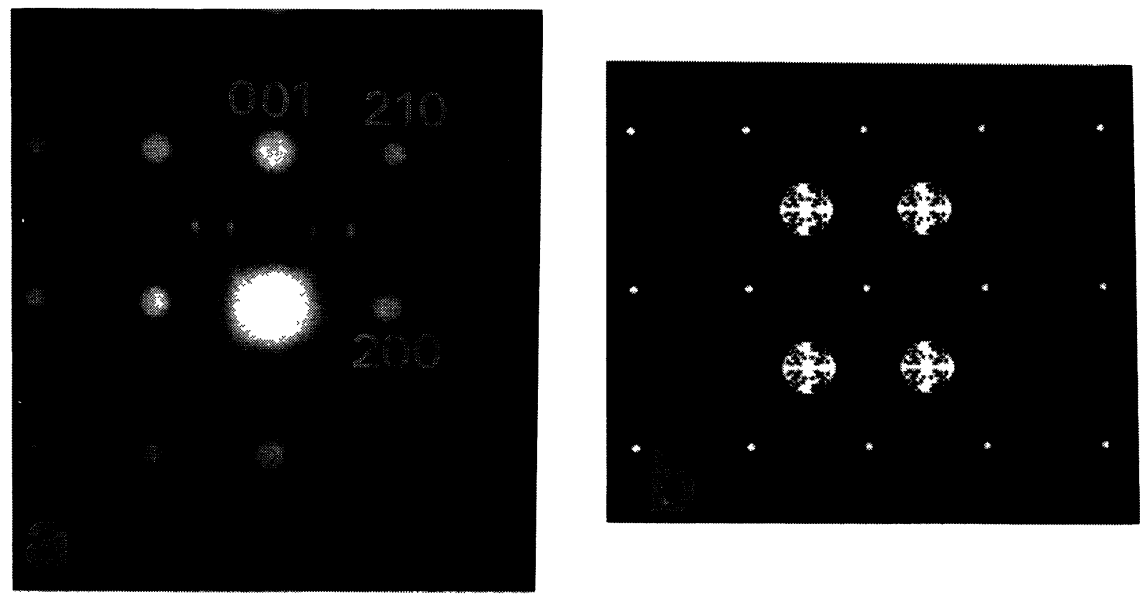

Fig. 9. - a) Experimental electron diffraction pattern of a mullite with composition $2 \mathrm{Al}_{2} \mathrm{O}_{3}-\mathrm{SiO}_{2}$. b) The large white circles indicate the region used for inverse Fourier transform. 

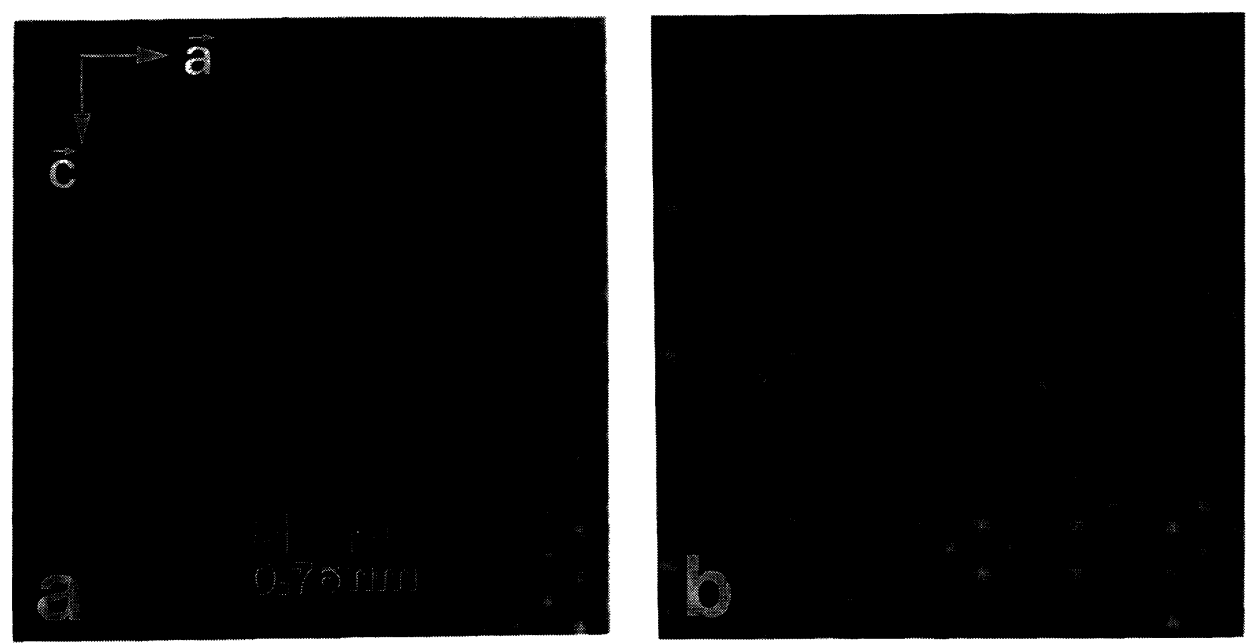

Fig. 10. - Mullite with composition $2 \mathrm{Al}_{2} \mathrm{O}_{3}-\mathrm{SiO}_{2}$. Observation plane (010) : a) HRTEM image,

b) image reconstructed by Fourier inversion using the circular masks in figure $9 \mathrm{~b}$.

\section{References}

[1] Revcolevschi A., Dhalenne G. and Michel D., External and internal surfaces of metal oxides, Mater. Sci. Forum (Trans Tech. Pub.) 29 (1988) 173-198.

[2] CORNIER-QUIQUENDON M., Dynamical theory of the diffraction of fast electrons by crystals and quasicrystals, Thesis University Paris VI (1988).

[3] MaZerolles L., Michel D. and Portier R., J. Am. Ceram. Soc. 69 (1986) 252.

[4] MAZEROLles L., Heterophase interfaces between refractory oxides. Structure and influence on the mechanical behaviour, Thesis University Paris VI (1988).

[5] MAZEROlles L., Michel D. and PORTIER R., Silicates Industriels (1988) p. 97.

[6] Michel D., MAZEROLles L. and PORTIER R., Mullite and Mullite Matrix Composites, Ceramic Transitions, S. Somiya, R. F. Davis, J. A. Pask Eds. (American Ceramic Society) 6 (1990) 435-448.

[7] SCHRYVERS D., SRI KrishnA K., O'KeEFE M. A. and ThOMAS G., J. Mat. Res. 3 (1988) 1355.

[8] Epicier T., O'KeEFe M. A., ThOMAS G., TORReCillas R., J. Microsc. Spectrosc. Electron. 14 (1988) 54a.

[9] Hamid Rahman S. and Weichert H. T., Acta Cryst. B46 (1990) 139.

[10] EPICIER T., O’KEEFE M. A. and ThOMAS G., Acta Cryst. A46 (1990) 948.

[11] ANGel R. J. and PREWTtT C. T., Am. Mineral. 71 (1986) 1476.

[12] Yla-JAASKI J. and NiSSEN H. U., Phys. Chem. Minerals 10 (1983) 47.

[13] Kahn-Harari A., Abolhassani S., Michel D., MaZerolles L., Portier R. and Perez-Ramirez J. G., J. Solid. State Chem. 90 (1991) 234. 